\title{
MdMYB4, an R2R3-Type MYB Transcription Factor, Plays a Crucial Role in Cold and Salt Stress in Apple Calli
}

\author{
Ruigang Wu, Yi Wang, Ting Wu, Xuefeng Xu, and Zhenhai Han ${ }^{1}$ \\ Institute of Horticultural Plants, China Agricultural University, 2 Yuanmingyuan West Road, Haidian \\ District, Beijing 100193, P.R. China; and Key Laboratory of Biology and Genetic Improvement of \\ Horticultural Crops (Nutrition and physiology), Ministry of Agriculture, P.R. China
}

\begin{abstract}
AdDITIONAL INDEX wORDs. abiotic stress, positive regulatory, subcellular localization, transcriptional activation, transformation

ABSTRACT. MYB (v-myb avian myeloblastosis viral oncogene homologs) transcription factors (TFs) are involved in diverse physiological processes, including cell shape determination, cell differentiation, and secondary metabolism, as well as abiotic stress response. In the present study, MdMYB4, an R2R3-MYB protein that is a homolog of Arabidopsis thaliana MYB4, was identified and characterized. Quantitative real-time polymerase chain reaction (qRT-PCR) expression analysis demonstrated that $M d M Y B 4$ is extensively expressed in various apple (Malus domestica) tissues and that its expression is induced by cold, osmotic, and salt stress. An MdMYB4-GFP fusion protein was localized in the nucleus of transformed onion (Allium cepa) epidermal cells and had a certain transcriptional activation activity by yeast one-hybrid assay. Overexpression of the $M d M Y B 4$ gene remarkably enhanced the tolerance of stably transgenic apple calli to severe salt and cold stress, and both the relative conductivity and malondialdehyde (MDA) accumulation of transgenic calli under salt and cold stress were significantly lower than in the wild type control. Taken together, these results suggest that MdMYB4 may play a positive regulatory role in both cold and salt stress responses.
\end{abstract}

\begin{abstract}
Abiotic stresses, such as cold, drought, and high salinity, are common adverse environmental conditions that can severely limit plant growth and development, as well as crop production (Xie et al., 2010). As sessile organisms, plants have evolved a series of intricate mechanisms that allow them to perceive external signals and respond to complicated stress conditions, and many studies have reported that a large number of genes are responsive to abiotic stresses in higher plants (Kasuga et al., 2004). In general, these stress-induced genes are either directly or indirectly modulated by regulators that are components of signal transduction pathways related to abiotic stress (Shinozaki and Yamaguchi-Shinozaki, 1997). To date, a variety of such genes have been characterized, most of which have been reported to regulate the synthesis of diverse biological components, such as proline (Hmida-Sayari et al., 2005; Hong et al., 2000; Kishor et al., 1995), betaine (Kumar et al., 2004), carbohydrates (Almeida et al., 2007; Avonce et al., 2005), polyamines (Imai et al., 2004), and other osmolytes, all of which are related to environmental stress tolerance. In addition, the genes that encode regulators, such as the late embryogenesis abundant protein HVA1 (Bahieldin et al., 2005; Garay-Arroyo et al., 2000; Park et al., 2005; Sivamani et al., 2000) and calcium-dependent protein kinase (CDPK) genes (Ma and Wu, 2007; Wan et al., 2007; Zhang et al., 2005), can be induced by abiotic stress.
\end{abstract}

In plants, TFs play vital regulatory roles in abiotic stress responses by binding to the promoters of abiotic stress-responsive

Received for publication 17 Jan. 2017. Accepted for publication 3 May 2017. We are grateful to the Earmarked Fund for China Agriculture Research System (CARS-28), the Key Laboratory of Beijing Municipality of Stress Physiology and Molecular Biology for Fruit Trees, and the Beijing Collaborative Innovation Center for Eco-environmental Improvement with Forestry and Fruit Trees (CEFF-PXM2016-014207-000038).

${ }^{1}$ Corresponding author. E-mail: rschan@cau.edu.cn. genes (Gujjar et al., 2014; Jung et al., 2008; Umezawa et al., 2006). Plant MYB TFs, which act as the largest family of TFs and are involved in various plant-specific processes, such as cell shape determination, cell differentiation, and secondary metabolism (Gujjar et al., 2014), have been reported to play roles in the response of the model plant $A$. thaliana to abiotic stresses. These genes function via abscisic acid (ABA)-dependent or ABA-independent stress response pathways and include $A t M Y B 2$ and $A t M Y B 41$ (Abe et al., 2003; Lippold et al., 2009); AtMYB44/AtMYBR1, AtMYB60, AtMYB96, AtMYB 13, AtMYB15, AtMYB33, and AtMYB101 (Abe et al., 2003; Cominelli et al., 2005; Gujjar et al., 2014; Lippold et al., 2009); and AtMYB70, AtMYB73, and AtMYB77/AtMYBR2 (Park et al., 2011). In addition, stress-related MYB TF genes in rice (Oryza sativa) have been successively cloned and transformed into plants using transgenic techniques, and the heterologous expression of such genes has been reported to remarkably enhance the tolerance of transgenic plants to both cold and salt stress (Pasquali et al., 2008). In apple, the MYB TF family includes 229 genes, which were identified using genome-wide analysis, and the effects of abiotic stressors on the expression of 18 MYB genes have also been reported (Cao et al., 2013). Among these genes, the overexpression of apple MdoMYB121 (Cao et al., 2013) and MdSIMYB1 (Wang et al., 2014) have been reported to remarkably enhance the tolerance of transgenic apple plants to high salinity, drought, and cold stress. Because apple trees are highly heterozygous and genetically self-incompatible or incompatible with closely related cultivars, they are difficult to modify by conventional breeding techniques; however, with the accomplishment of a high-quality draft genome sequence (Velasco et al., 2010), a variety of genes, such as those encoding MYB TFs, can potentially be used as candidate genes for cultivating resistant and genetically improved varieties. 
However, very little is known about their functions in apple. Therefore, to examine whether the expression of apple $R 2 R 3-$ $M Y B$ genes could be induced by abiotic stress, we selected 11 other apple $R 2 R 3-M Y B$ genes from seven $R 2 R 3-M Y B$ subgroups and used qPCR analysis to analyze their expression in response to $\mathrm{NaCl}$, polyethylene glycol (PEG), and cold treatments (Cao et al., 2013). We subsequently isolated apple MdMYB4, owing to its relatively high expression under stress, which suggested that MdMYB4 plays a role in abiotic stress tolerance.

\section{Materials and Methods}

Plant materials and treatments. Root, stem, leaf, flower, and fruit tissues were collected from a 5-year-old 'Golden Delicious' own-rooted apple tree for tissue-specific expression of MdMYB4 gene under nonstress conditions. In vitro apple shoot cultures of 'Golden Delicious' were subcultured on Murashige and Skoog (MS) solid medium with $0.5 \mathrm{mg} \cdot \mathrm{L}^{-1}$ 6-benzylaminopurine and $0.1 \mathrm{mg} \cdot \mathrm{L}^{-1}$ naphthylacetate on a 4-week interval at $25{ }^{\circ} \mathrm{C}$ under a $16 / 8$-h light/dark photope$\operatorname{riod} \approx 25 \mu \mathrm{mol} \cdot \mathrm{m}^{-2} \cdot \mathrm{s}^{-1}$ supplied by white fluorescent light, as described by Cao et al. (2013). Four-week-old apple shoot cultures were treated with osmotic ( $2 \%$ PEG), salt (200 mM $\mathrm{NaCl})$, and cold $\left(4^{\circ} \mathrm{C}\right)$ stress, and afterward, young leaves were collected at $0,3,6,9,12$, and $24 \mathrm{~h}$ for the analysis of the expression level of 11 MdR2R3-MYB genes (Supplemental Table 1), according to the methods described by YamaguchiShinozaki and Shinozaki (1994). The 'Orin' apple callus was subcultured on an MS medium with an additional $1.0 \mathrm{mg} \cdot \mathrm{L}^{-1}$ 6-benzylaminopurine and $1.0 \mathrm{mg} \cdot \mathrm{L}^{-1} 2-4 \mathrm{~d}$.

Quantitative PCR assays. Total RNA was extracted from the tissues using the hot borate method described by Yao et al. (2007), and after treatment with RNase-free DNase, first-strand cDNA was synthesized using a PrimeScript First Strand cDNA Synthesis Kit (TaKaRa, Dalian, China). The transcript levels of MdMYB4 were then examined using qPCR assays with genespecific primers (Supplemental Table 1). The apple $18 S$ rRNA gene was used as a loading control, and three technical and three biological replicates were performed for each qPCR reaction.

Cloning and bioinformatics analysis. The full-length MdMYB4 sequence (MDP0000582174) was obtained from the Apple Genome Database (Jung et al., 2014), and leaves from the 'Golden Delicious' shoot culture materials were used for cloning of MdMYB4 cDNA (Supplemental Table 2). The 20- $\mu \mathrm{L}$ qRT-PCR reactions each contained $10 \mu \mathrm{L}$ mixture (TaKaRa), $1.0 \mu \mathrm{L}$ cDNA, $1.0 \mu \mathrm{L}$ of each primer $(10 \mu \mathrm{M})$, and $7 \mu \mathrm{L}$ distilled and deionized water $\left(\mathrm{ddH}_{2} \mathrm{O}\right)$. The amplification consisted of 34 cycles of $30 \mathrm{~s}$ at $94{ }^{\circ} \mathrm{C}, 30 \mathrm{~s}$ at $58^{\circ} \mathrm{C}, 30 \mathrm{~s}$ at $72{ }^{\circ} \mathrm{C}$, followed by a final extension step of $7 \mathrm{~min}$ at $72{ }^{\circ} \mathrm{C}$. The PCR product was purified and subcloned into the pEasySimple T1 vector (TaKaRa) and sequenced (UnitedGene, Shanghai, China). After confirmation of the accuracy of the full-length sequence, a homology search of the National Center for Biotechnology Information GenBank database was conducted using protein BLAST, and a phylogenetic tree was constructed using the neighbor-joining method in MEGA 5 (Tamura et al., 2011). Prediction of the number of amino acids and isoelectric point, amino acid sequence alignments, and main domain analysis were completed using DNAMAN V6 (Lynnon Biosoft, San Ramon, CA), and the functional element analysis of the $1.5 \mathrm{-kb}$ promoter region upstream of the start codon was completed using Plant-CARE database (Higo et al., 1999).

Preparation of Agrobacterium tumefaciens suspension. A single colony of A. tumefaciens strain EHA105 (Hood et al., 1993) was inoculated into liquid Luria-Bertani (LB) medium with $50 \mathrm{mg} \cdot \mathrm{L}^{-1}$ kanamycin and $100 \mathrm{mg} \cdot \mathrm{L}^{-1}$ rifampicin and grown for $16 \mathrm{~h}$ at $28^{\circ} \mathrm{C}$ on an orbital shaker at $180 \mathrm{rpm}$. The resulting bacterial solution was diluted to an optical density $(\mathrm{OD})_{600}=0.1-0.2$ in $50 \mathrm{~mL}$ LB with $100 \mu \mathrm{M}$ acetosyringone and incubated at $28{ }^{\circ} \mathrm{C}$ with shaking for another 5-6 h until a density of $\mathrm{OD}_{600}=0.5$ was obtained. The bacterial cultures were then centrifuged at $3000 g_{\mathrm{n}}$ for $5-6 \mathrm{~min}$ at $25^{\circ} \mathrm{C}$, after which the supernatant was discarded, and the bacterial pellet was resuspended in $10 \mathrm{mM} \mathrm{MgCl}_{2}$ to its original titer.

Subcellular localization of MoMYB4. The complete MdMYB4 open reading frame was PCR-amplified using primers that contained EcoRI and BamHI restriction sites (Supplemental Table 2) and cloned into upstream of green fluorescent protein (GFP) of vector pEZS-NL (Song et al., 2012) to create a fusion construct (p35S: MYB4-GFP). Both the fusion construct and the control vector (pEZS-NL) were introduced into A. tumefaciens EHA105 and transformed into onion epidermal cells, according to the method described by $\mathrm{Li}$ et al. (2002). After being cultured on an MS medium for $2 \mathrm{~d}$ at $28{ }^{\circ} \mathrm{C}$ in darkness, the transformed cells were visualized using a confocal microscope (LSM 510 META; Zeiss, Jena, Germany).

Transcriptional activation assay of MdMYB4 in yeast. The complete MdMYB4 open reading frame was amplified using PCR with primers that contained EcoRI and BamHI restriction sites (Supplemental Table 2), and subcloned into EcoRI- and BamHI-digested pGBKT7 vector. The verified recombinant vector was transformed into the yeast strain AH109 and grown on a synthetic dextrose medium without tryptophan or lacking both tryptophan and histidine. Positive clones were assayed for LacZ reporter gene activation, using 5-bromo-4-chloro-3-indoxyl-b-D-galactopyranoside (X-gal) as a substrate, and yeast cells transformed with empty pGBKT7 vector were assayed as a negative control (Zheng et al., 2009).

MDMYB4 OVEREXPRESSION VECTOR CONSTRUCTION AND APPLE CALLI TRANSFORMation. The complete sequence of the $35 S$ promoter was amplified from the pBI121 vector (Supplemental Table 2) and cloned into the pCAMBIA1304 vector. Then, the complete MdMYB4 sequence was amplified using PCR with primers containing $K p n I$ and $X b a I$ restriction sites, and cloned into the $p C A M B I A-35 S$ vector, which was digested using the same restriction enzymes. The resultant constructs ( $p$ CAMBIA-MYB4) was introduced into A. tumefaciens strain EHA105 and transformed into 'Orin' apple calli, as described by $\mathrm{Li}$ et al. (2002). After four replicates of hygromycin selection subculture on a 2-week interval, antibiotic-resistant calli were detected using PCR (Supplemental Table 2) and $\beta$-glucuronidase (GUS) assays.

Measurement of fresh weight and relative CONDUCTIVITY. The MdMYB4-transgenic and control calli were placed on solid subculture media with 0,100 , and $200 \mathrm{~mm} \mathrm{NaCl}$ treatment or at 4,15 , and $25^{\circ} \mathrm{C}$, and changes in the callus phenotypes and fresh weight were observed after $20 \mathrm{~d}$. To measure relative conductivity, as much as $1.0 \mathrm{~g}$ fresh callus from each culture was transferred to an MS solid medium supplemented with $200 \mathrm{~mm} \mathrm{NaCl}$ or MS solid medium treated 
with $4{ }^{\circ} \mathrm{C}$ for $4 \mathrm{~h}$ and then the relative electronic conductivity of each sample was measured using a conductometer (DDS-308; KangYi, Chengdu, China), and the relative conductivity of each culture was calculated as $R 1 / R 2 \times 100 \%$ (Qiu et al., 2002). Three technical and three biological replicates were performed for each measurement.

Measurement of MaLondialdehyde Content. Malondialdehyde contents in $M d M Y B 4$-transgenic and control apple calli under cold $\left(15^{\circ} \mathrm{C}\right)$ and $\mathrm{NaCl}(100 \mathrm{~mm})$ stress at the indicated treatment time was measured according to Hodges's method (Hodges et al., 1999). Briefly, the calli were homogenized in $5 \mathrm{~mL} \mathrm{10 \%}$ trichloroacetic acid and centrifuged at $12,000 \mathrm{~g}_{\mathrm{n}}$ for $10 \mathrm{~min}$. The clear supernatant $(2 \mathrm{~mL})$ from each callus sample was added to $4 \mathrm{~mL} 0.6 \%$ thiobarbituric acid (in 10\% trichloroacetic acid), and the reaction mixtures were incubated at $100{ }^{\circ} \mathrm{C}$ in a water bath for $15 \mathrm{~min}$. The reactions were ended by cooling them to room temperature, and the absorbance of the supernatants at 450, 532, and $600 \mathrm{~nm}$ was determined using an ultraviolet-vis (ultraviolet-vis) spectrophotometer (ultraviolet-2450; Daojin, Chendu, China). Finally, the concentration of MDA (moles per gram) was calculated as $C_{\mathrm{MDA}} \times V$, where $C_{\mathrm{MDA}}(\mathrm{M})=6.45\left(\mathrm{OD}_{532}-\mathrm{OD}_{600}\right)-0.56\left(\mathrm{OD}_{450}\right)$ and $V($ milliliters per gram) is the volume of extracting solution used per gram fresh callus. Three technical and three biological replicates were performed for each measurement.

STATistical ANALYSIS. All data were analyzed using analysis of variance (ANOVA) by SPSS Statistics (version 18.0; IBM Corp., Armonk, NY), and the graphics were produced in SigmaPlot (version 10.0; Systat Software, San Jose, CA).

\section{Results}

EXPRESSION OF 11 R2R3-MYB GENES IN APPLE UNDER ABIOTIC STRESS. To examine if the expression of apple $R 2 R 3$ $M Y B$ genes is induced by abiotic stress including $\mathrm{NaCl}, \mathrm{PEG}$, and cold treatments, 10 apple $R 2 R 3-M Y B$ gene models (MdMYB4, 42, 59, 93, 113, 131, 143, 151, 194, and 214) were chosen from stress-related subgroups, whereas another (MdMYB8) was chosen from the other subgroups (Cao et al., 2013). The results of the qRT-PCR analysis indicated that the transcription of each of the $M d M Y B$ genes was responsive to at least one of the three stress treatments (Fig. 1; Supplemental



Fig. 1. Effect of abiotic stress on the expression levels of $11 M d R 2 R 3-M Y B$ genes in leaves of 'Golden Delicious' apple. Expression levels were measured after $12 \mathrm{~h}$ or exposure to $200 \mathrm{~mm} \mathrm{NaCl}, 2 \%$ polyethylene glycol (PEG), or cold $\left(4{ }^{\circ} \mathrm{C}\right)$ treatments. Ten of the $M d R 2 R 3-M Y B$ genes were chosen from stressrelated subgroups, and $18 S \mathrm{rRNA}$ expression was used as an internal standard.
Fig. 1). Interestingly, the $M d M Y B 4$ transcripts were strongly induced by all stresses tested, which indicated that the stresses induced the expression of $M d M Y B 4$.

The EFFECT OF ABIOTIC STRESS ON MDMYB4 EXPRESSION. To further study the $M d M Y B 4$ gene as a TF, the regulatory regions of $M d M Y B 4$ were analyzed in detail, and the effects of abiotic stress at different time spans on the expression of $M d M Y B 4$ was analyzed using qRT-PCR. We identified a variety of hormonerelated response elements (Supplemental Table 3), including an ABA-responsive element (ABRE), CGTCA and TGACG motifs, TGA and TCA elements, stress-induced elements, such as $\mathrm{HSE}$, and $\mathrm{TC}$-rich repeats in the promoter region, which suggested that MdMYB4 expression may be induced by both abiotic stress and stress hormones. Furthermore, the expression of MdMYB4 in apple leaves cultured under salt $(200 \mathrm{~mm} \mathrm{NaCl})$, cold $\left(4{ }^{\circ} \mathrm{C}\right)$, and osmotic stress $(2 \%$ PEG) indicated that MdMYB4 transcription was markedly induced by all three abiotic stresses at different times (Fig. 2B-D).

In addition, the qRT-PCR results also indicated that MdMYB4 was widely expressed in apple tissues, including in root, stem, leaf, flower, and fruit tissue, with the lowest level of MdMYB4 expression observed in the leaves (Fig. 2A). The results suggested that $M d M Y B 4$ may play an important role in responding to cold and salt stress in apple.

IDENTIFICATION OF THE MDMYB4 GENE. To further investigate functional characterization of $M d M Y B 4$, the gene was isolated from apple cDNA template. Cloning and sequencing indicated that the full-length MdMYB4 cDNA was 495 bp (Fig. $3 \mathrm{~A})$, and further analyses predicted that the gene encoded a protein with 164 amino acid residues, a molecular mass of $18.3 \mathrm{kDa}$, and a $\mathrm{pI}$ of 10.34. In relation to other R2R3-MYB TFs in $A$. thaliana and apple, phylogenetic analysis indicated that MdMYB4 formed a cluster with AtMYB3, AtMYB4, AtMYB7, AtMYB32, MdMYB16, and MdMYB17 (Fig. 3B and C; Supplemental Fig. 2).

MoMYB4 LOCALization. To observe the subcellular localization of the MdMYB4 protein, the open reading frame of MdMYB4 was fused to the N-terminus of green fluorescence protein (GFP) in the pEZS-NL vector, and its expression was driven by a constitutive $35 S$ CaMV promoter. In onion epidermis cells transformed with the MdMYB4-GFP fusion construct, green fluorescence was exclusively observed in the
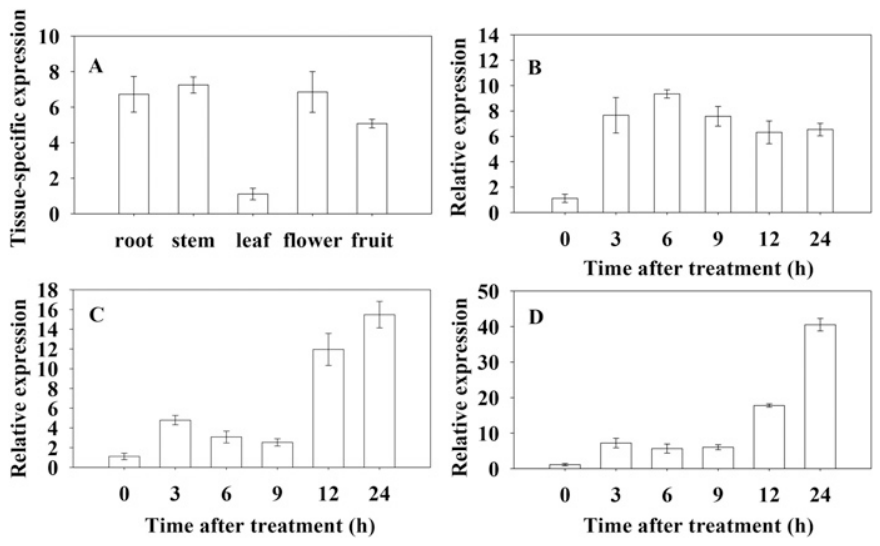

Fig. 2. Expression of MdMYB4 in apple. (A) Tissue-specific expression under nonstress conditions. (B-D) Expression in leaves of apple shoot cultures induced by salt $(200 \mathrm{~mm} \mathrm{NaCl})$, osmotic ( $2 \%$ polyethylene glycol), and cold $\left(4{ }^{\circ} \mathrm{C}\right)$ stress treatments, respectively. The expression of $18 \mathrm{~S}$ rRNA was used as an internal reference. Values are means $\pm \operatorname{SE}(n=3)$. 
nucleus (Fig. 4A and B), whereas fluorescence was detected in both the nucleus and the cytoplasm of the cells transformed with the control vector (Fig. 4C and D), thus indicating that MdMYB4 is localized to the nucleus.

Trans-activation of MoMYB4 in yeast. To determine whether MdMYB4 protein had transcriptional activation activity, the pGBKT7-MdMYB4 fusion protein was transformed

into yeast strain AH109, using empty pGBKT7 vector as a negative control. The results indicated that AH109/pGBKT7 could grow on an SD medium without tryptophan but not on an SD medium lacking both tryptophan and histidine (Fig. 5A and C); whereas AH109/pGBKT7-MdMYB4 could grow on an SD medium without tryptophan and without both tryptophan and histidine (Fig. 5B and D). In addition, the pGBKT7-MdMYB4 fusion protein also promoted the activity of the LacZ reporter gene (Fig. 5E). Therefore, MdMYB4 possesses the ability to selfactivate.

EFFECT OF MDMYB4 OVEREXPRESSION ON STRESS TOLERANCE IN APPLE CALLI. To confirm the functions of $M d M Y B 4$ in apple, MdMYB4-overexpressed transgenic apple calli were obtained and named MdMYB4OVX1-, MdMYB4-OVX2-, and MdMYB4OVX3-transgenic apple calli. To confirm that the calli were free from contamination by transgenic A. tumefaciens, specific primers were designed according to the sequences, excluding the vector T-DNA regions. However, no fragments of the expected size were PCR amplified. Therefore, the transgenic calli were free from potential contamination by $A$. tumefaciens. Those transgenic apple calli were subsequently detected using GUS staining assays (Fig. 6A). Based on the results of GUS staining and the growth status of calli, MdMYB4-OVX2 was used for further studies on abiotic stress tolerance. There was no significant difference in the growth patterns of MdMYB4-transgenic and control apple calli grown on an MS medium. When transferred to cold treatment $\left(15^{\circ} \mathrm{C}\right)$ or an MS medium supplemented with $100 \mathrm{~mm}$ $\mathrm{NaCl}$, the $M d M Y B 4$-transgenic calli exhibited greater tolerance to salt and cold stress than the control calli, as indicated by a greater
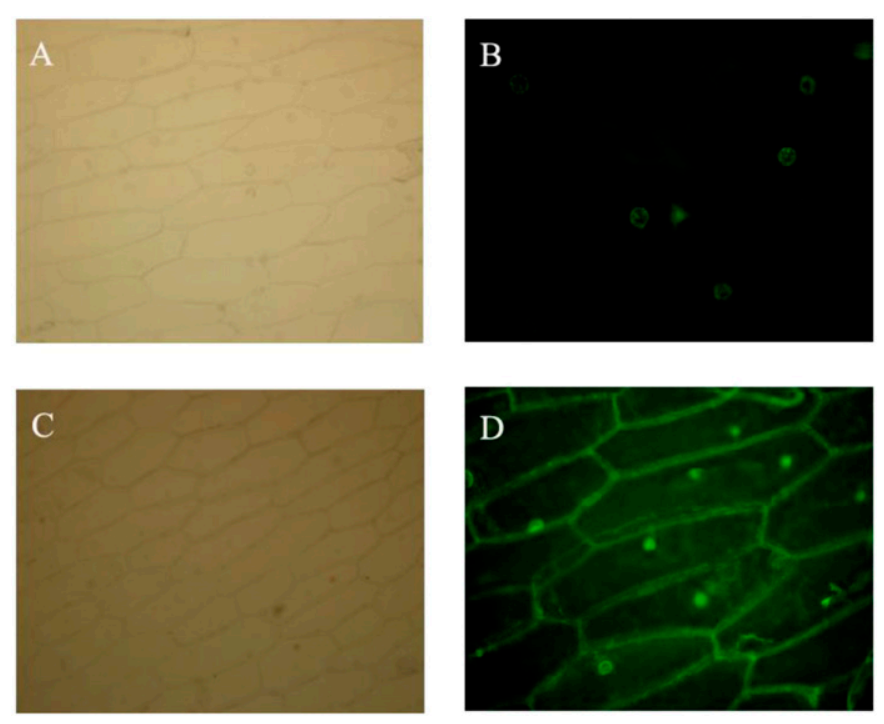

Fig. 4. Subcellular localization of MdMYB4-GFP fusion proteins transiently expressed in onion epidermal cells. Bright light (A and $\mathbf{C})$ and fluorescence (B and D) images of cells transformed with p35S:MdMYB4-GFP (A and B), and p35S:GFP plasmids ( $\mathbf{C}$ and $\mathbf{D})$. increase in fresh weight. However, when transferred to cold treatment $\left(4^{\circ} \mathrm{C}\right)$ or an MS medium supplemented with $200 \mathrm{~mm}$ $\mathrm{NaCl}$, it was impossible to obtain the same result, as the plant growth was arrested (Fig. 6B and C).

In addition, we also measured the relative conductivity and MDA content of MdMYB4-transgenic and control calli, since both are known indicators of membrane damage (Dong et al., 2011). The MdMYB4-transgenic and control calli exhibited nearly identical relative conductivity on an MS medium, whereas the relative conductivities of salt- and cold-stressed transgenic calli were lower than those of salt- and cold-stressed control calli (Fig. 6D); and both the MdMYB4-transgenic and control calli produced similar levels of MDA under normal conditions, whereas the MDA contents of salt- and coldstressed transgenic calli were lower than those of salt- and cold-stressed control calli (Fig. 7A-C). To confirm if the phenotypic alterations were due to the overexpression of MdMYB4, second line MdMYB4-OVX1-transgenic apple calli were used to perform experiments presented in Figs. 6 and 7, and similar results were obtained (Supplemental Fig. 3). Therefore, the expression level of MdMYB4 was negatively associated with both relative conductivity and MDA content, 

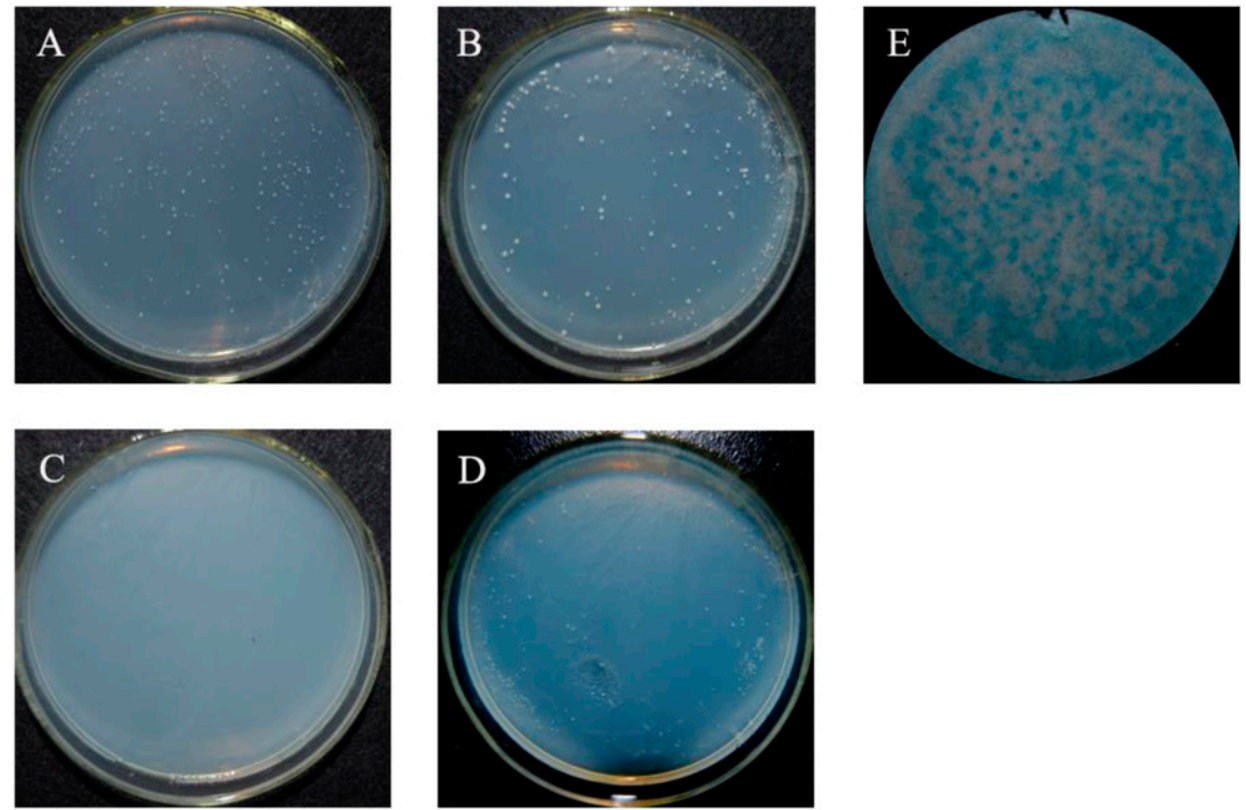

Fig. 5. Transcription activation ability of MdMYB4 in yeast cells. (A and C) Growth of yeast cells transfected with pGBKT7 on SD/-Trp or SD/-Trp-His medium, respectively. (B and D) Growth of yeast cells transfected with the pGBKT-MdMYB4 fusion protein on SD/-Trp or SD/-Trp-His medium, respectively. (E) Analysis of LacZ reporter gene activation, using $\mathrm{X}$-gal as the substrate.
A

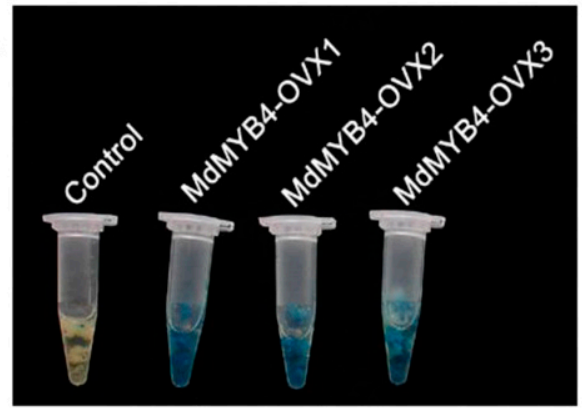

$\mathrm{B}$
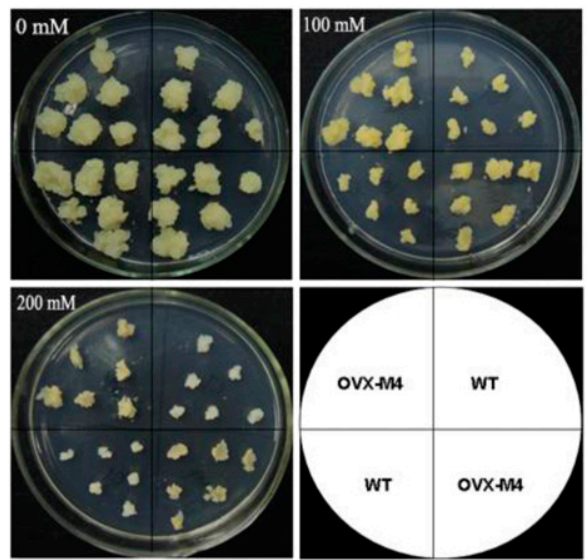
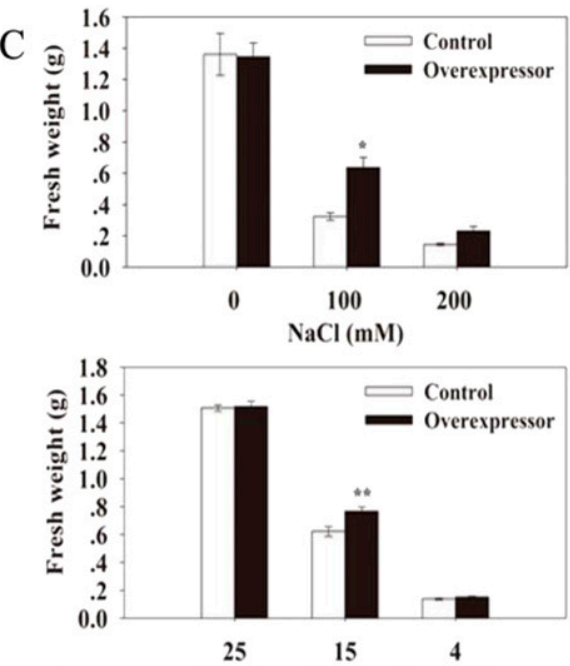

$\mathrm{D}$

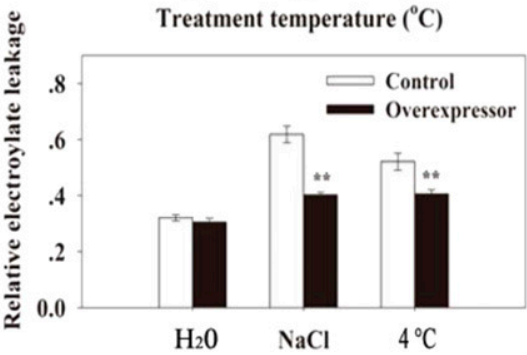

Fig. 6. Effect of $M d M Y B 4$ overexpression on salt and cold stress tolerance in MdMYB4-transgenic apple calli. (A) MdMYB4 expression. (B) Tolerance of calli to salt stress (MS medium with 0, 100, or $200 \mathrm{~mm} \mathrm{NaCl}$ ). Photographs taken at $20 \mathrm{~d}$ after treatment. (C) Fresh weight of salt- and cold-stressed apple calli. Values and error bars indicate means $\pm \mathrm{SE}(n=9)$. (D) Relative electronic conductivity of apple calli after $4 \mathrm{~h}$ of water $\left(\mathrm{H}_{2} \mathrm{O}\right)$, salt $(\mathrm{NaCl})$, and cold $\left(4^{\circ} \mathrm{C}\right)$ stress. Values and error bars indicate means $\pm \mathrm{SE}(n=3)$. Asterisks indicate values that are significantly different from those of the control group $(*=P<0.05, * *=P<0.01)$, according to ANOVA. which indicated that $M d M Y B 4$ is a positive regulator of tolerance to salt and cold stress.

\section{Discussion}

The MYB TF family is large and functionally diverse in higher plants and members have been identified in A. thaliana, rice, apple, and various other species (Du et al., 2011, 2012; Li et al., 2012). Substantial evidence suggests that the R2R3MYBs play important roles in abiotic stress tolerance in various plant species. These stress-induced genes are mostly distributed in some subfamilies, such as $\mathrm{S} 1,2,4,11$, 14, 20-23, and H5 (Cao et al., 2013); however, research regarding MYB TFs in apple has remained sparse. Subsequently, 229 apple MYB genes were identified through genome-wide analysis and divided into 45 subgroups and the expression of 18 genes in response to various abiotic stresses was examined (Cao et al., 2013). To further find the desired genes for genetic manipulation to enhance abiotic stress tolerance in fruit trees and other crops, 11 other apple R2R3MYB genes were chosen in the present study. Among them, 10 genes were from those stress-related subgroups, whereas another one from other subgroup, and the expression of 11 apple $R 2 R 3-M Y B$ genes from different subgroups (Fig. 1; Supplemental Fig. 2) was induced by multiple abiotic stresses, suggesting its involvement in the response and tolerance to abiotic stress, which is consistent with the fact that the expression of many MYB TF genes can be induced by abiotic stress in model plants (Chen et al., 2006). Besides, MdMYB4 transcripts were produced in all tested apple tissues, including in root, stem, leaf, flower, and fruit tissue (Fig. 2A), and markedly induced by all three abiotic stresses at different times (Fig. 2B-D), and it should be chosen as a candidate stress-inducible gene for further research.

When compared with other R2R3MYB TFs, phylogenetic analysis indicated that MdMYB4 formed a close cluster with $A$. thaliana subgroup S4, which includes AtMYB3, 


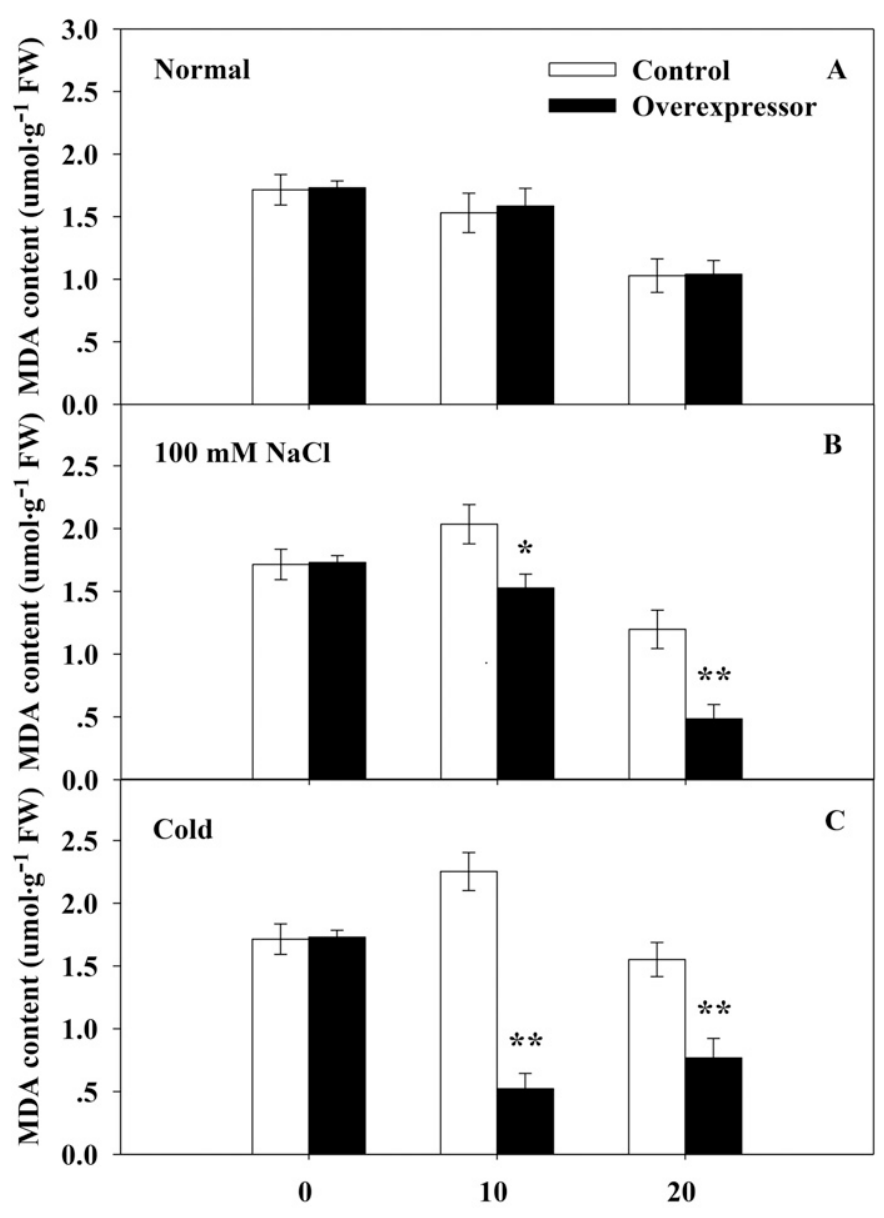

Treatment time (d)

Fig. 7. Effects of cold $\left(15^{\circ} \mathrm{C}\right)$ and $\mathrm{NaCl}(100 \mathrm{~mm})$ stress on the malondialdehyde (MDA) contents of $M d M Y B 4$-transgenic and control apple calli. Values and error bars indicate means $\pm \operatorname{SE}(n=3)$. Asterisks indicate values that are significantly different from those of the control group $(*=P<0.05$, ** $=P<$ 0.01 ), according to ANOVA.

AtMYB4, AtMYB7, and AtMYB32 (Fig. 3B). In reported studies, AtMYB4 has been shown to regulate sinapate ester biosynthesis in ultraviolet-exposed plants (Jin et al., 2000), and AtMYB7 is a new player in the regulation of ultravioletsunscreens (Fornalé et al., 2013), whereas AtMYB32 is required for pollen development (Preston et al., 2004). Meanwhile, the present study also determined that many hormonerelated and stress-induced response elements were present in MdMYB4 regulatory sequences, which suggests that the expression of the MdMYB4 protein may be induced by hormones and stresses.

In the present study, we also determined that MdMYB4 is localized to the nucleus in a subcellular manner (Fig. 4), which is consistent with the characteristics of TFs (Katiyar et al., 2012). Furthermore, our yeast one-hybrid results indicated that MdMYB4 functions as a transcriptional activator in plants and that it might regulate the expression of stress-related genes independently.

Previous results have also suggested that cold temperature $\left(4{ }^{\circ} \mathrm{C}\right)$ and $200 \mathrm{~mm} \mathrm{NaCl}$ are suitable treatments for gene expression analysis of in vitro apple shoot cultures (Cao et al., 2013; Hu et al., 2012; Wang et al., 2014). In the present study, when in vitro 'Golden Delicious' apple shoot cultures were exposed to 12 -h cold $\left(4{ }^{\circ} \mathrm{C}\right)$ and salt $(200 \mathrm{~mm} \mathrm{NaCl})$ stress treatments, the plants still grew well, and gene expression was strongly induced. Therefore, cold $\left(4^{\circ} \mathrm{C}\right)$ and salt $(200 \mathrm{mM}$ $\mathrm{NaCl}$ ) treatments were suitable for $M d M Y B 4$ expression analysis. When the long-term transgenic and control callus cultures were transferred to an MS solid medium that was supplemented with $\mathrm{NaCl}(200 \mathrm{~mm})$ or exposed to cold stress $\left(4{ }^{\circ} \mathrm{C}\right)$, growth was completely suppressed. However, when the transgenic and control calli were kept at $15^{\circ} \mathrm{C}$ or treated with $100 \mathrm{~mm} \mathrm{NaCl}$, the calli still grew well. Meanwhile, fresh weight exhibited significant differences. Therefore, the $15^{\circ} \mathrm{C}$ and $100 \mathrm{~mm} \mathrm{NaCl}$ treatments were used to measure MDA content and were deemed suitable for further functional analysis.

In addition, abiotic stress can result in membrane damage, as indicated by electrolyte leakage and MDA concentrations (Dong et al., 2011). In previous studies, enhanced tolerance to freezing and osmotic stress in OsMYB4- and MdMYB10transgenic plants, respectively, has been accompanied by lower MDA contents (Gao et al., 2011; Vannini et al., 2004). In addition, AtMYB2-transgenic A. thaliana exhibited enhanced tolerance to osmotic stress, as indicated by reduced electrolyte leakage (Abe et al., 2003). In the present study, transgenicMdMYB 4 calli produced less MDA and exhibited less electrolyte leakage than the control calli, which indicates that $M d M Y B 4$ enhances plant tolerance to multiple stresses.

Although overexpression of a novel apple $R 2 R 3-M Y B$ gene (MdMYB4) enhanced the tolerance of transgenic apple calli to salt and cold stress, whether field-grown transgenic apples will respond to stressors in the same way remains to be determined.

\section{Conclusion}

In conclusion, the overexpression of a novel apple $R 2 R 3$ $M Y B$ gene (MdMYB4) enhanced the tolerance of apple calli to salt and cold stress. Therefore, MdMYB4 should be considered a target gene for genetic manipulation aimed to enhance salt and cold stress tolerance in fruit trees, as well as in other crops.

\section{Literature Cited}

Abe, H., T. Urao, T. Ito, M. Seki, K. Shinozaki, and K. YamaguchiShinozaki. 2003. Arabidopsis AtMYC2 (bHLH) and AtMYB2 (MYB) function as transcriptional activators in abscisic acid signaling. Plant Cell 15:63-78.

Almeida, A.M., A.B. Silva, S.S. Araujo, L.A. Cardoso, D.M. Santos, J.M. Torne, J.M. Silva, M.J. Paul, and P.S. Fevereiro. 2007. Responses to water withdrawal of tobacco plants genetically engineered with the AtTPS1 gene: A special reference to photosynthetic parameters. Euphytica 154:113-126.

Avonce, N., B. Leyman, J. Thevelein, and G. Iturriaga. 2005. Trehalose metabolism and glucose sensing in plants. Biochem. Soc. Trans. 33:276-279.

Bahieldin, A., H.T. Mahfouz, H.F. Eissa, O.M. Saleh, A.M. Ramadan, I.A. Ahmed, W.E. Dyer, H.A. El-Itriby, and M.A. Madkour. 2005. Field evaluation of transgenic wheat plants stably expressing the HVA1 gene for drought tolerance. Physiol. Plant. 123:421-427.

Cao, Z.H., S.Z. Zhang, R.K. Wang, R.F. Zhang, and Y.J. Hao. 2013. Genome wide analysis of the apple MYB transcription factor family allows the identification of MdoMYB121 gene confering abiotic stress tolerance in plants. PLoS One 8:e69955, doi: 10.1371/journal. pone.0069955.

Chen, Y.H., X.Y. Yang, K. He, M.H. Liu, J.G. Li, Z.F. Gao, Z.Q. Lin, Y.F. Zhang, X.X. Wang, X.M. Qiu, Y.P. Shen, L. Zhang, X.H. Deng, 
J.C. Luo, X.W. Wang, Z.L. Chen, H.Y. Gu, and L.J. Qu. 2006. The MYB transcription factor superfamily of Arabidopsis: Expression analysis and phylogenetic comparison with the rice MYB family. Plant Mol. Biol. 60:107-124.

Cominelli, E., M. Galbiati, A. Vavasseur, L. Conti, T. Sala, M. Vuylsteke, N. Leonhardt, S.L. Dellaporta, and C. Tonelli. 2005. A guard-cell-specific MYB transcription factor regulates stomatal movements and plant drought tolerance. Curr. Biol. 15:1196-1200.

Dong, Q.L., D.D. Liu, X.H. An, D.G. Hu, Y.X. Yao, and Y.J. Hao. 2011. MdVHP1 encodes an apple vacuolar $\mathrm{H}^{+}$-PPase and enhances stress tolerance in transgenic apple callus and tomato. J. Plant Physiol. 168:2124-2133.

Du, H., B.R. Feng, S.S. Yang, Y.B. Huang, and Y.X. Tang. 2011. The R2R3-MYB transcription factor gene family in maize. PLoS One 7:1799-1823.

Du, H., S. Yang, B. Feng, L. Liu, Y. Tang, Y. Huang, and Z. Liang. 2012. Genome-wide analysis of the MYB transcription factor superfamily in soybean. BMC Plant Biol. 12:1-22.

Fornalé, S., E. Lopez, J.E. Salazar-Henao, P. Fernández-Nohales, J. Rigau, and D. Caparros-Ruiz. 2013. AtMYB7, a new player in the regulation of UV-sunscreens in Arabidopsis thaliana. Plant Cell Physiol. 55:507-516.

Gao, J.J., Z. Zhang, R.H. Peng, A.S. Xiong, J. Xu, B. Zhu, and Q.H. Yao. 2011. Forced expression of Mdmyb10, a myb transcription factor gene from apple, enhances tolerance to osmotic stress in transgenic Arabidopsis. Mol. Biol. Rpt. 38:205-211.

Garay-Arroyo, A., J.M. Colmenero-Flores, A. Garciarrubio, and A.A. Covarrubias. 2000. Highly hydrophilic proteins in prokaryotes and eukaryotes are common during conditions of water deficit. J. Biol. Chem. 275:5668-5674.

Gujjar, R.S., M. Akhtar, and M. Singh. 2014. Transcription factors in abiotic stress tolerance. Indian J. Plant. Physiol. 19:306-316.

Hmida-Sayari, A., R. Gargouri-Bouzid, A. Bidani, L. Jaoua, A. Savoure, and S. Jaoua. 2005. Overexpression of $\Delta$ 1-pyrroline-5carboxylate synthetase increases proline production and confers salt tolerance in transgenic potato plants. Plant Sci. 169:746-752.

Hodges, D.M., J.M. DeLong, C.F. Forney, and R.K. Prange. 1999. Improving the thiobarbituric acid-reactive-substances assay for estimating lipid peroxidation in plant tissues containing anthocyanin and other interfering compounds. Planta 207:604-611.

Hong, Z.L., K. Lakkineni, Z.M. Zhang, and D.P.S. Verma. 2000. Removal of feedback inhibition of $\Delta$ 1-pyrroline-5-carboxylate synthetase results in increased proline accumulation and protection of plants from osmotic stress. Plant Physiol. 122:11291136.

Hood, E.E., S.B. Gelvin, L.S. Melchers, and A. Hoekema. 1993. New Agrobacterium helper plasmids for gene transfer to plants. Transgenic Res. 2:208-218.

Hu, D.G., M. Li, H. Luo, Q.L. Dong, Y.X. Yao, C.X. You, and Y.J. Hao. 2012. Molecular cloning and functional characterization of MdSOS2 reveals its involvement in salt tolerance in apple callus and Arabidopsis. Plant Cell Rpt. 31:713-722.

Imai, A., T. Matsuyama, Y. Hanzawa, T. Akiyama, M. Tamaoki, H. Saji, Y. Shirano, T. Kato, H. Hayashi, D. Shibata, S. Tabata, Y. Komeda, and T. Takahashi. 2004. Spermidine synthase genes are essential for survival of Arabidopsis. Plant Physiol. 135:15651573.

Higo, K., Y. Ugawa, M. Iwamoto, and T. Korenaga. 1999. Plant cisacting regulatory DNA elements (PLACE) database: 1999. Nucleic Acids Res. 27:297-300.

Jin, H.L., E. Cominelli, P. Bailey, A. Parr, F. Mehrtens, J. Jones, C. Tonelli, B. Weisshaar, and C. Martin. 2000. Transcriptional repression by AtMYB4 controls production of UV-protecting sunscreens in Arabidopsis. EMBO J. 19:6150-6161.

Jung, C., J.S. Seo, S.W. Han, Y.J. Koo, C.H. Kim, S.I. Song, B.H. Nahm, Y. Do Choi, and J.J. Cheong. 2008. Overexpression of AtMYB44 enhances stomatal closure to confer abiotic stress tolerance in transgenic Arabidopsis. Plant Physiol. 146:623-635.
Jung, S., S.P. Ficklin, T. Lee, C.H. Cheng, A. Blenda, P. Zheng, and K. Evans. 2014. The genome database for rosaceae (GDR): Year 10 update. Nucleic Acids Res. 42:1237-1244.

Kasuga, M., S. Miura, K. Shinozaki, and K. Yamaguchi-Shinozaki. 2004. A combination of the Arabidopsis DREB1A gene and stressinducible $r d 29 \mathrm{~A}$ promoter improved drought- and low-temperature stress tolerance in tobacco by gene transfer. Plant Cell Physiol. 45:346-350.

Katiyar, A., S. Smita, S.K. Lenka, R. Rajwanshi, V. Chinnusamy, and K.C. Bansal. 2012. Genome-wide classification and expression analysis of MYB transcription factor families in rice and Arabidopsis. BMC Genet. 13:1-19.

Kishor, P.B.K., Z.L. Hong, G.H. Miao, C.A.A. Hu, and D.P.S. Verma. 1995. Overexpression of $\Delta$ 1-pyrroline-5-carboxylate synthetase increases proline production and confers osmotolerance in transgenic plants. Plant Physiol. 108:1387-1394.

Kumar, S., A. Dhingra, and H. Daniell. 2004. Plastid-expressed betaine aldehyde dehydrogenase gene in carrot cultured cells, roots, and leaves confers enhanced salt tolerance. Plant Physiol. 136:28432854.

Li, D.D., W. Shi, and X.X. Deng. 2002. Agrobacterium-mediated transformation of embryogenic calluses of Ponkan mandarin and the regeneration of plants containing the chimeric ribonuclease gene. Plant Cell Rpt. 21:153-156.

Li, Q., C. Zhang, J. Li, L. Wang, and Z. Ren. 2012. Genome-wide identification and characterization of R2R3MYB family in Cucumis sativus. PLoS One 7:e47576.

Lippold, F., D.H. Sanchez, M. Musialak, A. Schlereth, W.R. Scheible, D.K. Hincha, and M.K. Udvardi. 2009. AtMyb41 regulates transcriptional and metabolic responses to osmotic stress in Arabidopsis. Plant Physiol. 149:1761-1772.

Ma, S.Y. and W.H. Wu. 2007. AtCPK23 functions in Arabidopsis responses to drought and salt stresses. Plant Mol. Biol. 65:511-518.

Park, B.J., Z.C. Liu, A. Kanno, and T. Kameya. 2005. Increased tolerance to salt- and water-deficit stress in transgenic lettuce (Lactuca sativa L.) by constitutive expression of $L E A$. Plant Growth Regulat. 45:165-171.

Park, M.Y., J.Y. Kang, and S.Y. Kim. 2011. Overexpression of AtMYB52 confers ABA hypersensitivity and drought tolerance. Mol. Cells 31:447-454.

Pasquali, G., S. Biricolti, F. Locatelli, E. Baldoni, and M. Mattana. 2008. Osmyb4 expression improves adaptive responses to drought and cold stress in transgenic apples. Plant Cell Rpt. 27:1677-1686.

Preston, J., J. Wheeler, J. Heazlewood, S.F. Li, and R.W. Parish. 2004. AtMYB32 is required for normal pollen development in Arabidopsis thaliana. Plant J. 40:979-995.

Qiu, Q.S., Y. Guo, M.A. Dietrich, K.S. Schumaker, and J.K. Zhu. 2002. Regulation of SOS1, a plasma membrane $\mathrm{Na}^{+} / \mathrm{H}^{+}$exchanger in Arabidopsis thaliana, by SOS2 and SOS3. Proc. Natl. Acad. Sci. USA 99:8436-8441.

Shinozaki, K. and K. Yamaguchi-Shinozaki. 1997. Gene expression and signal transduction in water-stress response. Plant Physiol. 115:327-334.

Sivamani, E., A. Bahieldin, J.M. Wraith, T. Al-Niemi, W.E. Dyer, T.D. Ho, and R.D. Qu. 2000. Improved biomass productivity and water use efficiency under water deficit conditions in transgenic wheat constitutively expressing the barley HVA1 gene. Plant Sci. 155:1-9.

Song, S., Y. Chen, M. Zhao, and W.H. Zhang. 2012. A novel Medicago truncatula HD-Zip gene, MtHB2, is involved in abiotic stress responses. Environ. Expt. Bot. 80:1-9.

Tamura, K., D. Peterson, N. Peterson, G. Stecher, M. Nei, and S. Kumar. 2011. MEGA5: Molecular evolutionary genetics analysis using maximum likelihood, evolutionary distance, and maximum parsimony methods. Mol. Biol. Evol. 28:2731-2739.

Umezawa, T., M. Fujita, Y. Fujita, K. Yamaguchi-Shinozaki, and K. Shinozaki. 2006. Engineering drought tolerance in plants: Discovering and tailoring genes to unlock the future. Curr. Opin. Biotechnol. 17:113-122. 
Vannini, C., F. Locatelli, M. Bracale, E. Magnani, M. Marsoni, M. Osnato, M. Mattana, E. Baldoni, and I. Coraggio. 2004. Overexpression of the rice Osmyb4 gene increases chilling and freezing tolerance of Arabidopsis thaliana plants. Plant J. 37:115-127.

Velasco, R., A. Zharkikh, J. Affourtit, A. Dhingra, A. Cestaro, A. Kalyanaraman, P. Fontana, S.K. Bhatnagar, M. Troggio, D. Pruss, S. Salvi, M. Pindo, P. Baldi, S. Castelletti, M. Cavaiuolo, G. Coppola, F. Costa, V. Cova, A. Dal Ri, V. Goremykin, M. Komjanc, S. Longhi, P. Magnago, G. Malacarne, M. Malnoy, D. Micheletti, M. Moretto, M. Perazzolli, A. Si-Ammour, S. Vezzulli, E. Zini, G. Eldredge, L.M. Fitzgerald, N. Gutin, J. Lanchbury, T. Macalma, J.T. Mitchell, J. Reid, B. Wardell, C. Kodira, Z. Chen, B. Desany, F. Niazi, M. Palmer, T. Koepke, D. Jiwan, S. Schaeffer, V. Krishnan, C. Wu, V.T. Chu, S.T. King, J. Vick, Q. Tao, A. Mraz, A. Stormo, K. Stormo, R. Bogden, D. Ederle, A. Stella, A. Vecchietti, M.M. Kater, S. Masiero, P. Lasserre, Y. Lespinasse, A.C. Allan, V. Bus, D. Chagne, R.N. Crowhurst, A.P. Gleave, E. Lavezzo, J.A. Fawcett, S. Proost, P. Rouze, L. Sterck, S. Toppo, B. Lazzari, R.P. Hellens, C.E. Durel, A. Gutin, R.E. Bumgarner, S.E. Gardiner, M. Skolnick, M. Egholm, Y. Van de Peer, F. Salamini, and R. Viola. 2010. The genome of the domesticated apple (Malus $\times$ domestica Borkh.). Nat. Genet. 42:833.
Wan, B., Y. Lin, and T. Mou. 2007. Expression of rice $\mathrm{Ca}^{2+}$-dependent protein kinases $(C D P K s)$ genes under different environmental stresses. FEBS Lett. 581:1179-1189.

Wang, R.K., Z.H. Cao, and Y.J. Hao. 2014. Overexpression of a R2R3MYB gene MdSIMYB1 increases tolerance to multiple stresses in transgenic tobacco and apples. Physiol. Plant. 150:76-87.

Xie, Z., D. Li, L. Wang, F.D. Sack, and E. Grotewold. 2010. Role of the stomatal development regulators FLP/MYB88 in abiotic stress responses. Plant J. 64:731-739.

Yamaguchi-Shinozaki, K. and K. Shinozaki. 1994. A novel cis-acting element in an Arabidopsis gene is involved in responsiveness to drought. Plant Cell 6:251-264.

Yao, Y.X., M. Li, Z. Liu, Y.J. Hao, and H. Zhai. 2007. A novel gene, screened by cDNA-AFLP approach, contributes to lowering the acidity of fruit in apple. Plant Physiol. Biochem. 45:139-145.

Zhang, M., S.P. Liang, and Y.T. Lu. 2005. Cloning and functional characterization of $N t C P K 4$, a new tobacco calcium-dependent protein kinase. Biochim. Biophys. Acta 1729:174-185.

Zheng, X., B. Chen, G. Lu, and B. Han. 2009. Overexpression of a NAC transcription factor enhances rice drought and salt tolerance. Biochem. Biophys. Res. Commun. 379:985-989. 


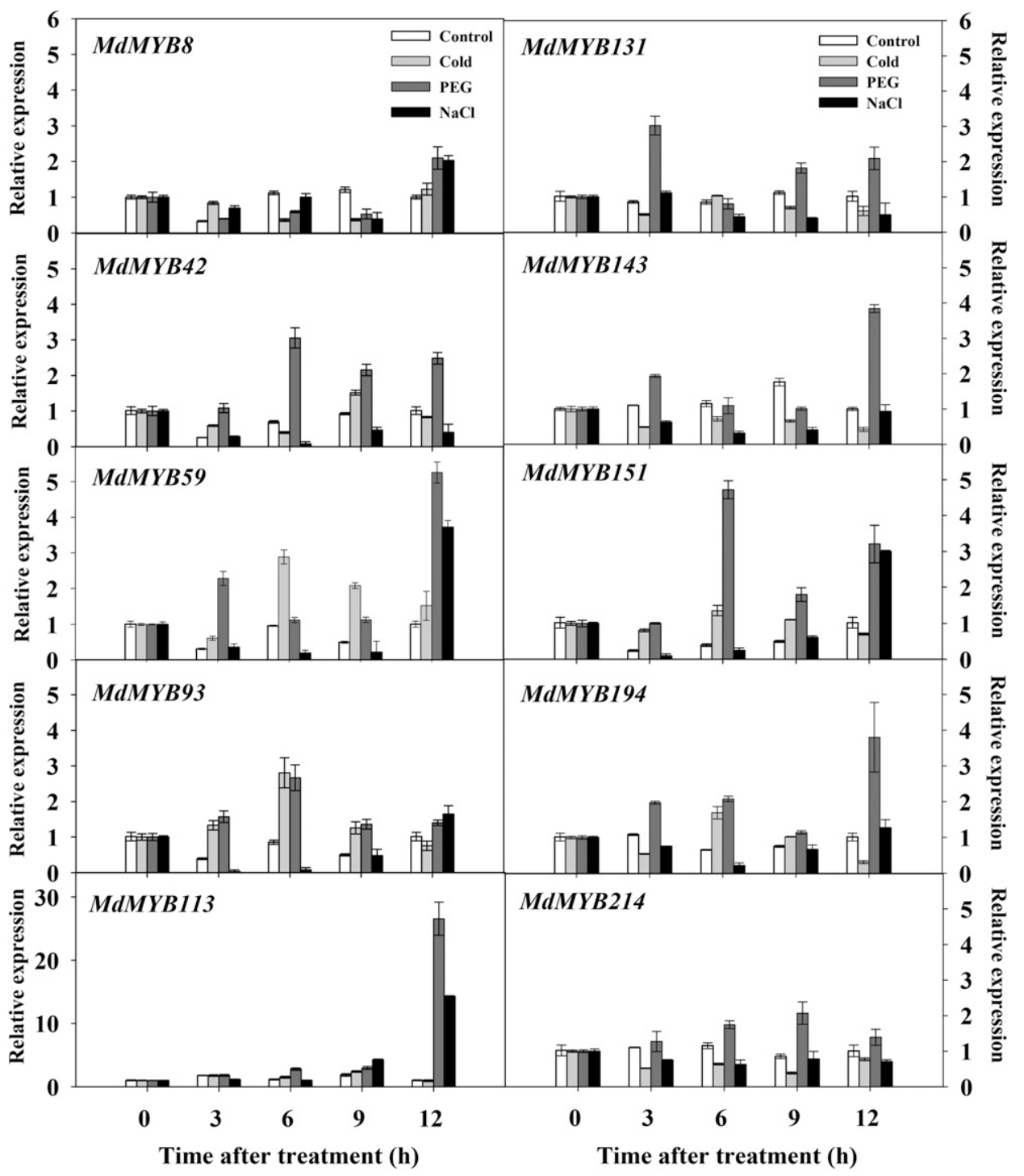

Supplemental Fig. 1. Effect of abiotic stress on the expression levels of $10 M d R 2 R 3-M Y B$ genes in leaves of 'Golden Delicious' apple. Apple shoot cultures were treated with osmotic $\left(2 \%\right.$ polyethylene glycol), salt $(200 \mathrm{~mm} \mathrm{NaCl})$, and cold $\left(4{ }^{\circ} \mathrm{C}\right)$ stress, and then young leaves were collected at $0,0,3,6,9$, and $12 \mathrm{~h}$ respectively for the expression levels of $10 M d R 2 R 3-M Y B$ genes, and $18 S$ rRNA expression was used as an internal standard. 


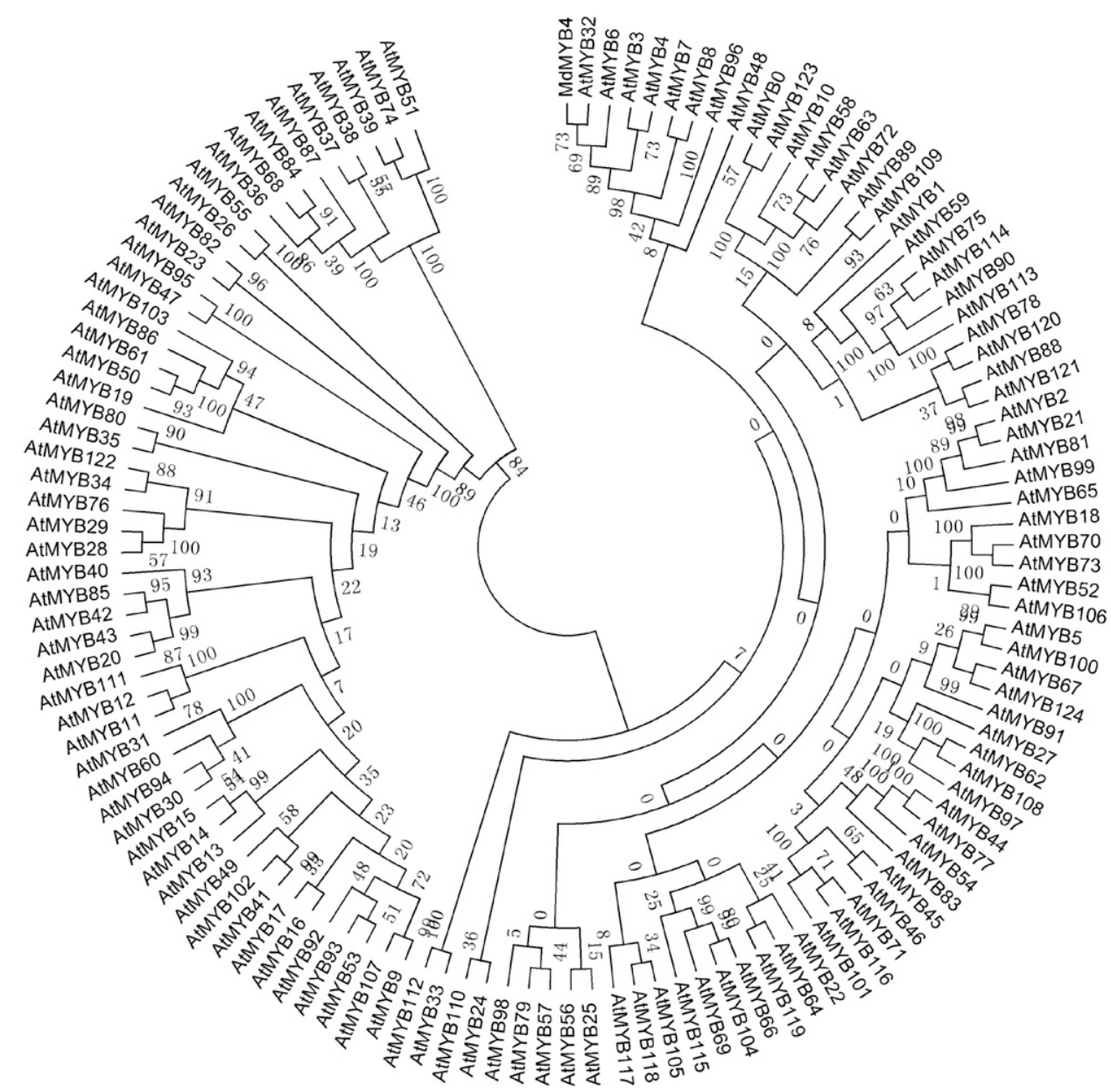

Supplemental Fig. 2. MdMYB4 phylogenetic tree with R2R3-MYB proteins in Arabidopsis thaliana. 
A

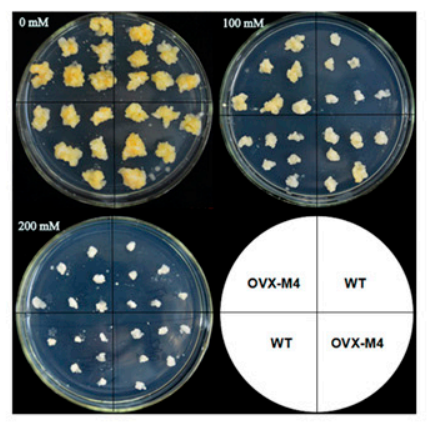

$\mathrm{B}$

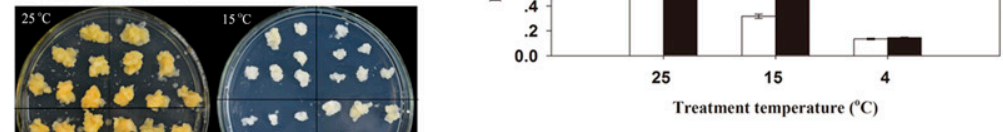

$\mathrm{E}$

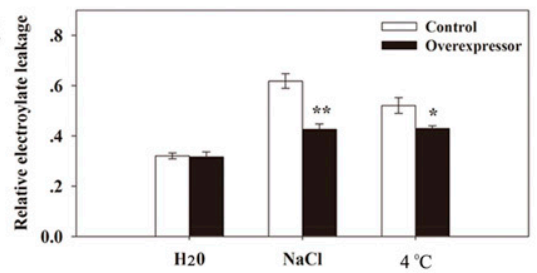

F

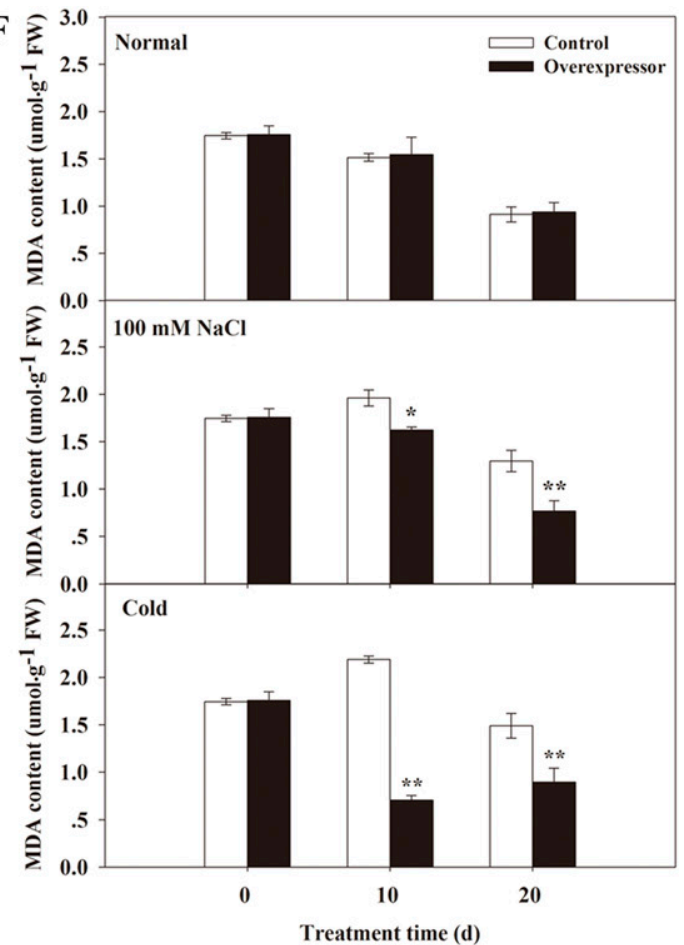

Supplemental Fig. 3. Effect of MdMYB4 overexpression on salt and cold stress tolerance in MdMYB4-transgenic apple calli. (A and B) Tolerance of calli to salt stress (MS medium with 0,100 , or $200 \mathrm{~mm} \mathrm{NaCl})$ or cold stress $\left(25,15\right.$, or $\left.4{ }^{\circ} \mathrm{C}\right)$. Photographs taken at $20 \mathrm{~d}$ after treatment. (C and D) Fresh weight of salt- and cold-stressed apple calli. Values and error bars indicate means $\pm \mathrm{SE}(\mathrm{n}=9)$. (E) Relative electronic conductivity of apple calli after $4 \mathrm{~h}$ of water $\left(\mathrm{H}_{2} \mathrm{O}\right)$, salt $(\mathrm{NaCl})$, and cold $\left(4^{\circ} \mathrm{C}\right)$ stress. Values and error bars indicate means $\pm \mathrm{SE}(n=3)$. (F) Effects of cold $\left(15^{\circ} \mathrm{C}\right)$ and $\mathrm{NaCl}(100 \mathrm{mM})$ stress on the malondialdehyde $(\mathrm{MDA})$ contents of MdMYB4-transgenic and control apple calli. Values and error bars indicate means $\pm \operatorname{SE}(n=3)$. Asterisks indicate values that are significantly different from those of the control group $(*=P<0.05, * *=P<0.01)$, according to ANOVA.

Supplemental Table 1. Primer sequences used for expression analysis of $11 M d R 2 R 3-M Y B$ genes under abiotic stress treatments (Cao et al., 2013).

\begin{tabular}{|c|c|c|c|}
\hline \multirow[b]{2}{*}{ Gene } & \multirow[b]{2}{*}{ Subgroup } & \multicolumn{2}{|c|}{ Sequence $\left(5^{\prime}-3^{\prime}\right)$} \\
\hline & & Forward & Reverse \\
\hline$\overline{M d M Y B 8}$ & $\mathrm{~S} 23$ & GGCCTTGAGAGTAATGGGATAAG & TCTAGGCACCTGGGTTGATA \\
\hline MdMYB42 & S14 & TTGGAAGCAGGTGGTCAATAA & GTGTTGCTTCCTCGGTATGA \\
\hline MdMYB93 & S4 & GGGAAGAACCGATAACGAGATT & GTGGTTGTTGACGGGTTTATG \\
\hline$M d M Y B 113$ & $\mathrm{~S} 2$ & GGTCGCACAGACAATGAAATAAA & GAAACAGGCACACAATCCAAG \\
\hline$M d M Y B 131$ & $\mathrm{~S} 1$ & GGTCCTGGTAATTGGAGATCAG & CAAGTGGGTGTTCCAGTAGTT \\
\hline$M d M Y B 151$ & $\mathrm{~S} 20$ & CACCGCCACTAATTCCTCTATC & GGTGATACCTGAGTCCCAAAC \\
\hline MdMYB194 & $\mathrm{S} 22$ & CAGCAGTAACAGCGAGAAGAA & TCCTTATCATCCCTTGCATCAC \\
\hline$M d M Y B 214$ & $\mathrm{~S} 1$ & CTGTGGCAAATACTGCGAATAG & CAGCAGCACCTTCATCAAAC \\
\hline$M d M Y B 4$ & S4 & TGTGAAAAGGCTCACACCAACAAAG & TTGCCATGATTGAGATCAGGTCTAAGGT \\
\hline $18 S$ & - & CCTCCAATGGATCCTCGTTA & ACACGGGGAGGTAGTGACAA \\
\hline
\end{tabular}


Supplemental Table 2. Primers used for cloning, subcellular localization analysis, vector construction, transgenic confirmation, and expression analysis.

\begin{tabular}{|c|c|c|}
\hline \multirow[b]{2}{*}{ Primers } & \multicolumn{2}{|c|}{ Sequences $\left(5^{\prime}-3^{\prime}\right)$} \\
\hline & Forward & Reverse \\
\hline \multirow[t]{2}{*}{ Subcellular localization } & CCGGAATTCATGGGAAGATCTCCTTGCTG & CGCGGATCCAATCATAGATTGAAAGAAGG \\
\hline & EcoRI site is underlined & Bam $\overline{\mathrm{HI}}$ site is underlined \\
\hline $\begin{array}{l}\text { Self-activating yeast } \\
\text { capability }\end{array}$ & EcoRI site is underlined & BamHI site is underlined \\
\hline \multirow{2}{*}{$\begin{array}{l}\text { Construction of } \\
\text { overexpression } \\
\text { vector }\end{array}$} & CGGGGTACCATGGGAAGATCTCCTTGCTGTGAAA & GCTCTAGATCAATCATAGATTGAAAGAAGGTGA \\
\hline & KpnI site is underlined & $\mathrm{XbaI}$ site is underlined \\
\hline $\begin{array}{l}\text { Quantitative RT-PCR } \\
\text { analysis }\end{array}$ & TGTGAAAAGGCTCACACCAACAAAG & TTGCCATGATTGAGATCAGGTCTAAGGT \\
\hline $18 \mathrm{~S}$ & CCTCCAATGGATCCTCGTTA & ACACGGGGAGGTAGTGACAA \\
\hline $35 \mathrm{~S}$ promoter & AGATTAGCCTTTTCAATTTCAGAAA & CGTGTTCTCTCCAAATGAAATGAAC \\
\hline $\begin{array}{l}\text { Cloning of } M d M Y B 4 \\
\text { gene }\end{array}$ & ATGGGAAGATCTCCTTGCTGTGAAA & TCAATCATAGATTGAAAGAAGGTGA \\
\hline
\end{tabular}

Supplemental Table 3. cis-acting elements identified in the MdMYB4 sequence.

\begin{tabular}{lclll}
\hline Site name & Strand & \multicolumn{2}{c}{ Position } & \multicolumn{1}{c}{ Sequence } \\
\hline ABRE & + & $81 / 1126$ & CACGTG & cis-acting element involved in the abscisic acid responsiveness \\
ACE & - & 862 & AAAACGTTTA & cis-acting element involved in light responsiveness \\
I-Box & + & $513 / 663 / 596$ & CTCTTATGCT & cis-acting regulatory element involved in light responsiveness \\
HSE & + & 911 & AGAAAATTCG & cis-acting element involved in heat stress responsiveness \\
TC-rich repeats & - & 908 & ATTTTCTTCA & cis-acting element involved in defense and stress responsiveness \\
TGA element & - & $9 / 280 / 1054 / 1325$ & AACGAC & auxin-responsive element \\
TCA element & + & $441 / 1486$ & GAGAAGAATA & cis-acting element involved in salicylic acid responsiveness \\
& & $414 / 662 / 1459$ & CCATCTTTTT & \\
TGACG motif & + & $17 / 1041 / 1062$ & TGACG & cis-acting regulatory element involved in the MeJA responsiveness \\
\hline
\end{tabular}

